\title{
Model of optimal behaviour in fish larvae predicts that food availability determines survival, but not growth
}

\author{
Øyvind Fiksen ${ }^{1,2, *}$, Christian Jørgensen $^{2}$ \\ ${ }^{1}$ Department of Biology, University of Bergen, Pb 7803, 5020 Bergen, Norway \\ ${ }^{2}$ Uni Research, 5020 Bergen, Norway
}

\begin{abstract}
How do growth and survival of larval fish depend on the availability of zooplankton prey? This question connects plankton ecology to fisheries science and is typically answered by the classical 'match/mismatch' hypothesis for explaining recruitment variability to fish populations. In field and experimental data, however, the effects of food abundance on growth are not always unequivocal. Here, we present a detailed state-dependent optimality model of larval cod Gadus morhua in a water column with environmental gradients and circadian light cycles. Larval feeding rates and predation risk both depend on ambient light, body size, swimming activity and depth position, which together describe trade-offs between growth and survival from realistic mechanisms. The model finds the optimal depth (vertical migration) and swimming activity that maximize survival probability to a given size $(15 \mathrm{~mm})$. These optimal behaviours in turn determine food intake, gut fullness, growth and survival over time. The model predicts that increasing food leads to increasing survival, whereas growth remains high except when food availability is very low. When food is more abundant, larvae select deeper and safer habitats and are less active to avoid predation. This can explain why prey abundance and larval fish growth are often not strongly correlated in field studies, although there is still an important effect of prey abundance on recruitment success through its effect on predation rates.
\end{abstract}

KEY WORDS: Larval fish · Behaviour · Growth · Mortality $\cdot$ Recruitment $\cdot$ Trade-off

\section{INTRODUCTION}

Larval fish are particularly vulnerable to predation, and much attention has been devoted to understanding survival during early life stages. Even small changes in survival can make the difference between strong and weak year-classes available for harvesting. Hjort (1914) emphasized that co-occurrence of firstfeeding larvae and abundant zooplankton prey would be beneficial for growth and survival and ultimately recruitment, a perspective that is also embodied in the match/mismatch hypothesis (Cushing 1990). As Leggett \& Frank (2008) pointed out recently, the match/ mismatch hypothesis can be broken down to 3 perspectives, all of which have had great influence on the development of fisheries oceanography. First, fish lar- vae seem to have a stronger size-dependency in their mortality rate than other aquatic organisms of comparable size (McGurk 1986). This led to the 'bigger is better' hypothesis stating that larger body size confers advantages in terms of survival (Miller et al. 1988, Bailey \& Houde 1989). A second perspective emphasized that size is not constant, such that faster growth reduced the duration of the larval stages and thereby cumulative predation; this is often referred to as the 'stage duration' hypothesis (Houde 1997). Finally, the role of growth rate was emphasized by Takasuka et al. (2003), who observed across sizes that slower-growing larvae died from predation faster than larvae with higher growth rates. This 'growth selectivity' hypothesis suggested that rapid growth in itself is advantageous for survival. 
Each of these 3 hypotheses are perfectly plausible, but they are coherent with evolutionary theory only if one ignores an important element from theoretical ecology: the behaviourally mediated trade-off between growth and survival (Conover \& Schultz 1997, Perez \& Munch 2010). Typically, faster growth, increased foraging, or greater starvation tolerance can be achieved through some behavioural act such as habitat choice, but a common consequence is that it compromises survival (McNamara \& Houston 1987, Houston et al. 1993). For fish larvae, the habitats where food can be found often overlap with the habitats where larvae are exposed to predators. The perspective of behavioural ecology therefore challenges the 3 hypotheses above: (1) that 'bigger is better' is not necessarily true as mortality may be higher for larger larvae if small larvae are cautious and large larvae take risks, size-dependence may furthermore depend on the type of predator; (2) a shorter 'stage duration' is often traded off against survival; and (3) there is evidence that survival is maximized when growth is optimized (Arendt 1997, Dmitriew 2011), implying that 'growth selectivity' is only adaptive up to a certain point; at growth rates above the optimum, reduced growth will likely increase survival.

The bridging of mechanistic modelling and evolutionary reasoning challenges the view that environmental variables have a given and inescapable effect on growth or survival. In contrast, a perspective that includes behavioural ecology implies that variability in environmental conditions operate to produce a setting in which larval fish face behavioural trade-offs with survival consequences. Consequently, the optimal behaviour is likely to change with environmental conditions. It is important to include both the environmental setting and the adaptive behavioural response to fully understand the environmental effect on recruitment success. This point may be illustrated by the following seemingly contradicting observations. Good years for recruitment typically occur when fish eggs and larvae temporally match production peaks and occurrence of zooplankton prey (Cushing 1990). For example, across a 42 yr time series from the North Sea there was a clear correlation between recruitment of Atlantic cod Gadus morhua and an index of availability of zooplankton prey (Beaugrand et al. 2003). This seemingly contrasts with observations that surviving larval and early juvenile cod in a range of cases tend to have grown at temperature-limited rates regardless of food availability (Folkvord 2005). But if growth is unchanged, there is no variation in size at age as required by the 'bigger is better' hypothesis, the 'stage duration' hypothesis would imply that survival to a certain age should be unchanged too, and the 'growth selectivity' hypothesis would conclude that the potential for faster growth has been realized as there is no further variation in growth.
There is thus little help offered by these hypotheses in explaining the patterns observed by Beaugrand et al. (2003) and Folkvord (2005). However, if a trade-off between growth and survival is invoked, then these observations are consistent: larvae alter their behaviour towards more risky foraging strategies to maintain growth if food is scarce. Larval survival therefore increases when prey is abundant.

In the present study, we constructed a model which predicts the state-dependent optimal behaviour of larval cod in vertical environmental gradients typical for the pelagic. We use larval Atlantic cod as our model species, but the predictions are relevant to any organism with flexible behaviour, trade-offs between growth and survival, and high mortality rates. We assess how prey availability will influence growth, survival, and recruitment success by finding optimal and flexible activity levels and habitat selection of larvae. Our aim is to show that a model built around the trade-off between growth and predation from behavioural ecology can explain many of the observed patterns in larval fish growth and survival. The model embraces the 'bigger is better', the 'stage-duration', and the 'growth selectivity' concepts from fisheries oceanography. We have deliberately made the model rich in mechanistic detail to promote comparison and interaction with field and experimental studies. For example, by introducing 3 types of predators, our model outlines how (1) visual predation is of greater importance for larger larvae as they are easier to spot, (2) ambush tactile predators are most efficient on fish larvae that move a lot, and (3) cruising or entangling tactile predators are most dangerous for small fish larvae with limited escape capabilities. These sources of predation vary in importance due to growth and the day-night cycle in light levels. The model makes rich predictions that we hope will stimulate further discussion that combines theory and observation, and it underscores the link between biological oceanography, prey availability and fisheries science.

\section{THE MODEL}

Overview. Which traits or behaviours are potential candidates for a growth-survival trade-off in larval fish? The pelagic, where most fish larvae spend at least part of their early life, is not a homogeneous place. Physical characteristics of the environment vary continuously, particularly in the vertical dimension where temperature, foraging efficiency and predation risk often show strong gradients over short distances. In particular, light is an important, diurnally varying gradient that affects both food detection and visibility towards predators (Clark \& Levy 1988). By selecting 
vertical position, fish larvae influence their own feeding, growth and risk of predation. Another consequential behaviour is activity level, or the cruising velocity, where high activity is associated with increased encounter rates with both prey and predators (Bailey \& Houde 1989).

The model simulates a larval fish from first feeding at $5 \mathrm{~mm}$ until it reaches a body length of $15 \mathrm{~mm}$, a size where larval cod metamorphose to more juvenile traits (Pedersen \& Falk-Petersen 1992). This takes more than 4 wk depending on environmental conditions and behaviour. The larva is modelled in a water column with vertical and temporal gradients of light illumination, which generates spatial and temporal gradients of foraging efficiency and predation risk from larger fish. In addition, larval fish are susceptible to entangling and ambush predators, and the ambush predation rate is proportional to larval motility due to vertical migration and foraging. Optimal behaviour is found in a state-variable dynamic-programming model that maximizes survival probability to a given size, and we solve the model for a range of prey densities and 3 prey distribution patterns. An optimal depth and activity level are found for each hour of the day and for each combination of the following individual states: body length, stomach fullness and current depth. In the present sudy, we analyze the relationship between prey availability and survival. The model gives quite detailed mechanistic descriptions of foraging, predation, growth, behaviour and physiology. The mechanistic formulations in the submodels have been presented in detail elsewhere (Fiksen \& MacKenzie 2002, Fiksen et al. 2007, Kristiansen et al. 2007, 2009), allowing us to focus here on how zooplankton abundance influences recruitment success in a pelagic larval fish with a flexible behavioural repertoire.

Environment. For planktonic organisms, the environment (e.g. temperature, light, prey availability and predator density) typically varies more in the vertical than in the horizontal direction, with implications for feeding, growth and survival rates. We have ignored gradients such as salinity, turbulence and temperature; here we keep the vertical profiles of the environment simple for tractability (Fig. 1). We find larval fitness and behaviour under uniform, deep or shallow prey distributions (Fig. 1). Light decays at a fixed rate with depth (diffuse attenua- tion). We mimic the hourly irradiance cycle around spring equinox at $70^{\circ}$ latitude. Prey abundance is specified in terms of biomass per volume sea water, recalculated into numbers $\mathrm{m}^{-3}$ assuming typical prey mass and length for each larval size category. The environment remains fixed over the whole larval period.

State variables and fitness. The dynamic state variables are gut fullness $g$ (in fractions of full), body size 1 $(\mathrm{mm})$, vertical position $z(\mathrm{~m})$ of the larva, and time of the day $h$ (hour). The immediate vertical position and time of the day need to be included as state variables because the larvae are constrained by swimming velocity. All state variables are updated every hour as a consequence of behaviour and environmental effects on foraging success and physiology.

We use dynamic programming (Mangel \& Clark 1988, Houston \& McNamara 1999) to find optimal depth $z^{\prime *}$ and activity $a^{*}$ for each combination of state variables. We assume larval fish maximize the probability of survival up to a given body length $l_{\max }$ by continuously adjusting their vertical position $z$ in the water column and activity a (cruising speed to detect prey; $\mathrm{m} \mathrm{s}^{-1}$ ) to optimal values. This means that the terminal

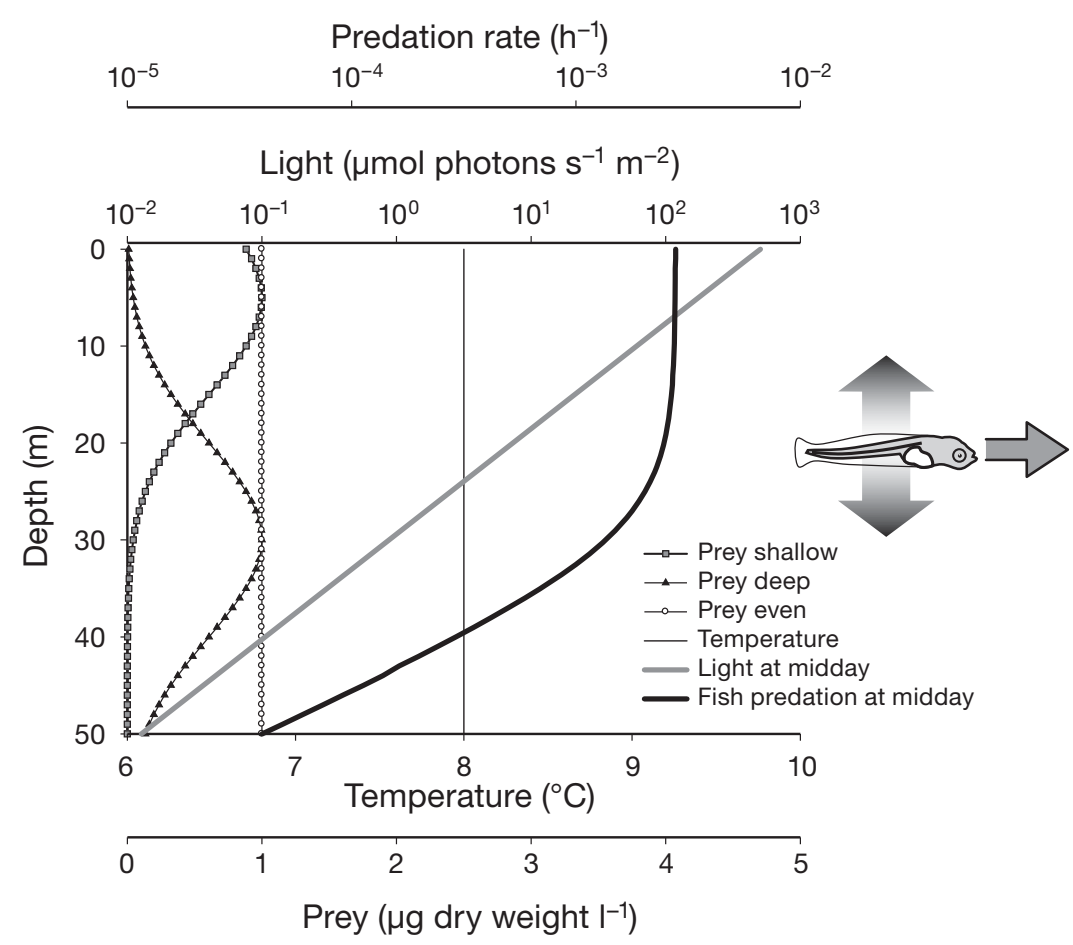

Fig. 1. Basic environmental gradients, with homogeneous temperature and deep, shallow or evenly distributed prey, shown for the lowest level of prey abundance only. Light decays with depth at a constant rate of $0.2 \mathrm{~m}^{-1}$, a value typical for coastal water in spring (see Huse \& Fiksen 2010 for details). The detection distance and search efficiency of visual predators saturates at high values of ambient light (see Aksnes \& Utne 1997), and therefore the predation rate $\left(\mathrm{h}^{-1}\right)$ will decrease exponentially with depth from dusk to dawn. The larval behaviour is vertical position and swimming activity (cartoon) 
fitness $V$ at the time horizon $h_{\max }$ is set to 0 for all states, while the fitness of the target size $l_{\max }$ will always be 1 :

$$
\left\{\begin{array}{c}
V\left(g, l, z, h_{\max }\right)=0, \text { for all } l<l_{\max } \\
V(g, l, z, h)=1, \text { for } l=l_{\max }
\end{array}\right\}
$$

We iterate backwards in time to find fitness for all states within $1 \mathrm{~d}$, i.e. for each combination of the states $g, l$ and $z$ the model finds the behavioural combination of new depth $z^{\prime}$ and activity level a that maximizes expected survival until length $l_{\max }$ :

$$
V(g, l, z, h)=\max _{z^{\prime}, a}\left[P\left(l, z, z^{\prime}, a, h\right) \cdot V\left(g^{\prime}, l^{\prime}, z^{\prime}, h+1\right)\right]
$$

Here, $g^{\prime}, l^{\prime}$ and $z^{\prime}$ are new states in the next time step $h+1$, the function $\max _{z^{\prime}, a}[$ ] finds the behavioural actions $z^{\prime}$ and $a$ that in combination maximize the expression within the square brackets, and the probability of survival $P$ depends on size, depth, vertical migration $(z-$ $\left.z^{\prime}\right)$, activity and time of day (see below). We repeat the iteration for consecutive days by setting $V(g, l, z$, $\left.h_{\max }\right)=V(g, l, z, 0)$ between each day. For each diel cycle, the optimal behavioural actions $a^{*}(g, l, z, h)$ and $z^{\prime *}(g, l, z, h)$ are stored for each state combination (11 gut states, 10 length categories, 50 depth intervals and 24 time steps [i.e. $3600 \mathrm{~s}$ each], in total 132000 elements). We then compare the behavioural matrices between sequential days; during the first diel cycles the optimal behaviour will keep changing, but at some point it converges and becomes independent of the initial terminal reward function and effects of the horizon (see Houston \& McNamara 1999, p. 43). At this point, the backward iteration is terminated, and the 2 matrices of optimal habitat selection $z^{\prime *}$ and activity $a^{*}$ are stored. Finally, consequences of optimal behaviours are simulated forward in time for single individuals, starting at $5 \mathrm{~mm}$ body length.

Foraging activity and vertical migration. The search or clearance rate $\beta$ (volume scanned for prey per unit time; $\mathrm{m}^{3} \mathrm{~s}^{-1}$ ) is implemented as:

$$
\beta(l, z, a, u, h)=0.5 \pi R_{1}^{2}(l, z, h) \max (a, u)
$$

Here, the first part represents the cross-sectional area of a cylinder is searched where the radius is determined by prey detection distance of the larva, $R_{1}(\mathrm{~m})$. Prey is only detected by looking up and to the sides, therefore the 0.5 factor. The swimming speed used is whichever is largest of cruise velocity a or migration velocity $u\left(=\left|z^{\prime}-z\right| / 3600 ; \mathrm{m} \mathrm{s}^{-1}\right)$, allowing the larva to search for prey while migrating between depths. Prey detection distance, or visual range, of the larvae, $R_{1}$, depends on ambient light, prey size, larval size (visual acuity) and light scattering (see Aksnes \& Utne 1997, Fiksen \& MacKenzie 2002, Huse \& Fiksen 2010 for details):

$$
R_{1}^{2}=\kappa_{1} A_{1} \mathrm{e}^{-c R_{1}} \frac{E_{\mathrm{b}}(z, h)}{K_{\mathrm{e}}+E_{\mathrm{b}}(z, h)}
$$

where $\kappa_{1}$ is the product of prey contrast against the

\begin{tabular}{|c|c|c|c|}
\hline Symbol & Variable or parameter & Unit & Value \\
\hline$A_{1}$ & Prey image area $\left(0.75 \times 0.05 \times 0.025 l^{2}\right)$ & $\mathrm{m}^{2}$ & $0.018751^{2}$ \\
\hline a & Larval activity, i.e. swimming speed & $1 \mathrm{~s}^{-1}$ & {$[0,1]$} \\
\hline$f_{\mathrm{a}}$ & Fraction of invertebrate mortality caused by ambush predators & Dimensionless & 0.5 \\
\hline$b$ & Size-dependence in larval mortality (McGurk 1986) & Dimensionless & -0.85 \\
\hline$\beta$ & Larval clearance rate & $\mathrm{m}^{-3} \mathrm{~s}^{-1}$ & Eq. (3) \\
\hline$C$ & Beam attenuation (at $2 \mathrm{mg} \mathrm{chl} \mathrm{a} \mathrm{m}^{-3}$; see Huse \& Fiksen 2010) & $\mathrm{m}^{-1}$ & \\
\hline$h$ & Hour of the day & & {$[0,24]$} \\
\hline$\gamma$ & Prey handling time & $\mathrm{s}$ & 1 \\
\hline$i$ & Ingestion rate & Prey s ${ }^{-1}$ & Eq. (5) \\
\hline$E_{\mathrm{b}}(z, h)$ & Ambient irradiance & $\mu \mathrm{mol} \mathrm{m} \mathrm{m}^{-2} \mathrm{~s}^{-1}$ & {$[0,500]$} \\
\hline$d_{\mathrm{f}}$ & Density of fish predators & Fish $\mathrm{m}^{-3}$ & $10^{-4}$ \\
\hline$\kappa$ & Scaling parameter for $R_{f}$ & Dimensionless & 3000 \\
\hline$k$ & Mortality parameter (McGurk 1986) & $\mathrm{s}^{-1}$ (g dry weight $)^{-b}$ & $2.5 \times 10^{-9}$ \\
\hline$K_{\mathrm{e}}$ & Light-sensitivity of larva and piscivore (Fiksen \& MacKenzie 2002) & $\mu \mathrm{mol} \mathrm{m}{ }^{-2} \mathrm{~s}^{-1}$ & 1 \\
\hline 1 & Length of larva & $\mathrm{m}$ & {$\left[5 \times 10^{-3}, 15 \times 10^{-3}\right]$} \\
\hline$l_{\max }$ & Target length, i.e. max. length modelled & $\mathrm{m}$ & $15 \times 10^{-3}$ \\
\hline$m_{i}, m_{\mathrm{f}}$ & Mortality rate from invertebrates or fish & $\mathrm{s}^{-1}$ & Eqs. (4), (5) \\
\hline$N(z)$ & Prey density in depth z & Prey $\mathrm{m}^{-3}$ & Fig. 1 \\
\hline$u$ & Migration activity, in fractions of max. swimming velocity & $l \mathrm{~s}^{-1}$ & {$[0,1]$} \\
\hline$u_{\mathrm{f}}$ & Fish predator cruising velocity & $\mathrm{m} \mathrm{s}^{-1}$ & 0.1 \\
\hline$P$ & Survival probability & Dimensionless & Eq. (7) \\
\hline$R_{\mathrm{l}}, R_{\mathrm{f}}$ & Visual detection distance of larva and piscivore & $\mathrm{m}$ & Eqs. (3), (6) \\
\hline$g$ & Gut fullness & Dimensionless & \\
\hline$V$ & Fitness, defined as expected survival until $l_{\max }$ & Dimensionless & Eqs. (1), (2) \\
\hline$z$ & Depth & $\mathrm{m}$ & \\
\hline
\end{tabular}
background (0.3) and the eye-sensitivity of the larvae increasing with length such that $R_{\mathrm{l}}$ is always 1 body

Table 1. List of key parameters, variables, units and values 
length 1 for a $0.015 \mathrm{~mm}^{2}$ naupliar prey image area under non-limiting light. The prey image area $A_{1}$ is the prey length $\times$ width $\times 0.75$, and $K_{\mathrm{e}}$ defines how $R_{\mathrm{l}}$ depends on radiation $E_{\mathrm{b}}$ in depth $z$ at time $h$, and $c$ is scattering of image-forming light (see Table 1). A key point is that larvae can increase search rate by remaining higher up in the water column. Our focus is on the effects of prey availability in terms of biomass, and we let the size of prey change proportionally with the larva (5\% of larval length; Munk 1997), while the total prey concentration in terms of biomass remains fixed. The clearance rate in Eq. (3) enters a Holling disk foraging model to give ingestion rate $i$ (prey $\mathrm{s}^{-1}$ ), assuming a capture probability of 0.2 (Fiksen \& MacKenzie 2002):

$$
i(l, z, a, u, h)=\frac{\beta(l, z, a, u, h) \cdot N(z)}{1+\gamma \cdot \beta(l, z, a, u, h) \cdot N(z)}
$$

where $\gamma\left(\right.$ s prey $\left.^{-1}\right)$ is handling time and $N(z)$ (prey $\mathrm{m}^{-3}$ ) prey concentration at depth $z$. Although increasing the cruising speed or migration activity will increase ingestion rates, it also has costs in terms of energy and more encounters with predators. We let energy costs be proportional to swimming speed, with a doubling of basic metabolic rate from none to maximum activity or migration. Activity also enhances predation risk (see below).

Predation from invertebrates. The predation cost of activity is related to the risk of encountering ambush or entangling invertebrate predators. Small larval fish have a range of invertebrate predators, which often detect their prey by detecting hydromechanical signals generated from prey movements through the water (Kiørboe 2008). Smaller larvae are typically most susceptible to such predators, and predation rates decrease rapidly with body size (Bailey \& Houde 1989). McGurk (1986) compiled data on mortality rates of fish eggs and larvae, showing a decline in mortality with size that was much stronger than for other organisms of comparable size. We let predation rate from invertebrate predators $m_{\mathrm{i}}\left(\mathrm{s}^{-1}\right)$ depend on body length, activity level and vertical migration distance in fractions of maximum migration capacity (1 body length $\mathrm{s}^{-1}$ ):

$$
m_{\mathrm{i}}(l, a, u)=k l^{b}\left\{[\max (a, u) / l] \cdot f_{\mathrm{a}}+\left(1-f_{\mathrm{a}}\right)\right\}
$$

Here, $k l^{b}$ is the body-length dependent mortality expected from the McGurk (1986) relationship and $f_{\mathrm{a}}$ is the fraction of invertebrate predation mortality caused by ambush predators. This formulation assumes movement of larvae is only increasing mortality from ambush predators (e.g. jellies, chaetognaths), while cruising invertebrates (e.g. euphausids), responsible for the fraction $1-f_{\mathrm{a}}$ of the size-dependent predation, are moving much faster than the larva. The expression $\max (a, u) / 1$ takes values between 0 and 1 , such that the predation rates match the regression in McGurk (1986) if the larvae is fully active or if all invertebrate predators are cruising $\left(f_{\mathrm{a}}=0\right)$. We acknowledge that this is an ad hoc formulation, but it captures essential properties of how body size and larval swimming behaviour influence predation risk from invertebrates, while avoiding an explicit representation of distribution and density of invertebrate predators. As a sensitivity analysis we also ran the model with a fixed, size-independent mortality rate from sources other than fish.

Predation from fish. The encounter or predation rate from visual predators, typically fish, $m_{\mathrm{f}}\left(\mathrm{s}^{-1}\right)$ can be expressed as:

$$
m_{\mathrm{f}}(l, z, h)=0.5 \pi\left[R_{\mathrm{f}}(l, z, h)\right]^{2} u_{\mathrm{f}} d_{\mathrm{f}}
$$

where $R_{\mathrm{f}}$ is visual range of the fish, $u_{\mathrm{f}}$ is cruising velocity, and $d_{\mathrm{f}}$ fish density (see Table 1 ). We assume that visual predators have a uniform probability of appearing anywhere in the water column; this assumption is justified by Eq. (7) because the linear effect of fish density of visual predators is overweighed by the much stronger effect of light on search efficiency and visual detection distance. We furthermore assume that fish predators swim much faster than the fish larva and capture the larva with certainty at encounter. The fish detection distance $R_{\mathrm{f}}$ is found iteratively from the same model as for larval foraging, but with parameters indexed by 'l' in Eq. (4) replaced with values specific for fish predation. In particular, $\kappa_{\mathrm{f}}$ is now the product of larval contrast against the background (0.3), a fixed eye-sensitivity of the predatory fish $\left(5 \times 10^{4}\right)$ and the length-to-width factor of the larva (0.2). Note that predation risk from fish will be proportional to the squared larval length in a fixed light environment.

Survival probability over each time-step thus becomes a function of larval length, depth position, activity and time of the day:

$$
P\left(l, z, z^{\prime}, a, h\right)=\mathrm{e}^{-m_{\mathrm{i}}(l, a, u)+m_{\mathrm{f}}(l, z, h)}
$$

Simulations. For each environmental setting or parameter combination, we first run the backwards optimization procedure to find the optimal behavioural strategies $a^{*}(g, l, z, h)$ and $z^{\prime *}(g, l, z, h)$. These strategies are large look-up tables that specify which action to choose given the current individual state. Thereafter, the consequences of these strategies are found by simulating individuals following these optimal strategies in forward time, starting from first feeding at a body length of $5 \mathrm{~mm}$ and continuing until they reach a size of $15 \mathrm{~mm}$. During these forward simulations we record internal states, habitat choice, behaviour and survival, and it is data from these forward simulations that are presented in Figs. 2 \& 3. In Fig. 4, the process of backwards optimization and forward simulation was repeated for many parameter values, where each point on the graphs represents summary statistics for one for- 
ward simulation. Throughout, our focus is how behaviour, growth and survival change with prey availability for an adaptive larva; we therefore present results for a low food (3 mg dry wt $\mathrm{m}^{-3}$ ) and a high food scenario (10 mg dry wt $\mathrm{m}^{-3}$ ).

The model is written in the Fortran programming language, and the source code is available in the Supplement at www.int-res.com/articles/suppl/m432 p207_supp/.

\section{RESULTS}

\section{Behavioural ontogeny in relation to food abundance}

Generally, the youngest larvae remain close to the surface in the model. As they develop, their optimal diel vertical migrations become gradually deeper and they search more actively for food (Fig. 2). When contrasting the low food scenario (Fig. 2a) with the situation with more food, (1) low-food larvae require about $4 \mathrm{~d}$ more to reach $15 \mathrm{~mm}$, (2) as young they stay closer to the surface for at least some portion of the daily cycle, (3) their excursions to depth are shallower and of shorter duration, (4) their activity level is higher from early age, and (5) during late ontogeny they rarely go all the way to the surface during the night. At high food abundance, larger larva have more extensive migrations, as it becomes profitable to forage in the decaying light moving up in the water column at dusk and down at dawn, thus capitalizing on the anti-predator window (sensu Clark \& Levy 1988). The model predicts that larvae forage just enough to avoid growth reductions due to empty guts during night, except at very low food levels where sub-maximal growth becomes optimal.

A more detailed inspection of the diel patterns of behaviour, growth, predation and individual state illustrates how the optimal responses vary with time of day, with age, and between the high- and low-food situations (Fig. 3). Common for the high- and low-food scenarios is that small larvae are active throughout the day, while larger larvae concentrate their activity at dawn and dusk, with a supplementary meal around midday to avoid emptying the gut. In all cases, growth becomes limited by assimilation from the gut in early morning, particularly for older larvae at low food levels.

\section{Trade-offs involved with foraging}

Foraging is typically associated with a habitat shift upward in the water column. As small larvae form a tiny image they are not so vulnerable to visual predation and can remain closer to the surface, thereby
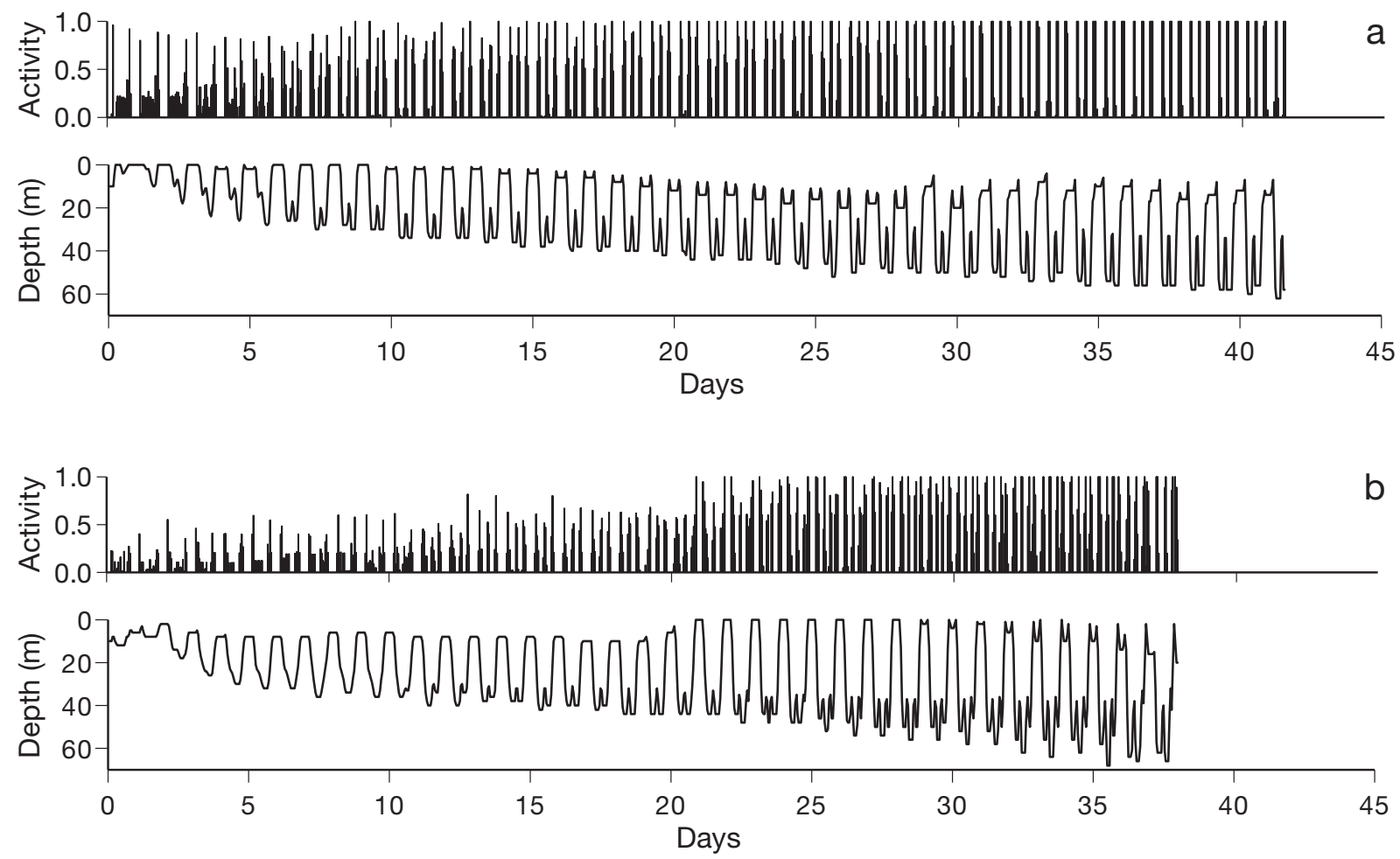

Fig. 2. Swimming activity (upper panels) and depth selection (lower panels), for a larva growing from 5 to $15 \mathrm{~mm}$ body length under (a) low (3 $\mathrm{mg}$ prey $\mathrm{m}^{-3}$ ) and (b) high $\left(10 \mathrm{mg}\right.$ prey $\left.\mathrm{m}^{-3}\right)$ food abundance. Prey was uniformly distributed 


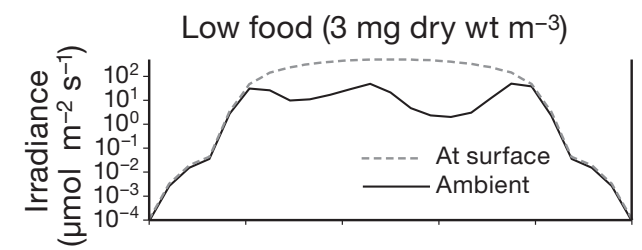

High food (10 mg dry wt $\left.\mathrm{m}^{-3}\right) \quad$ a
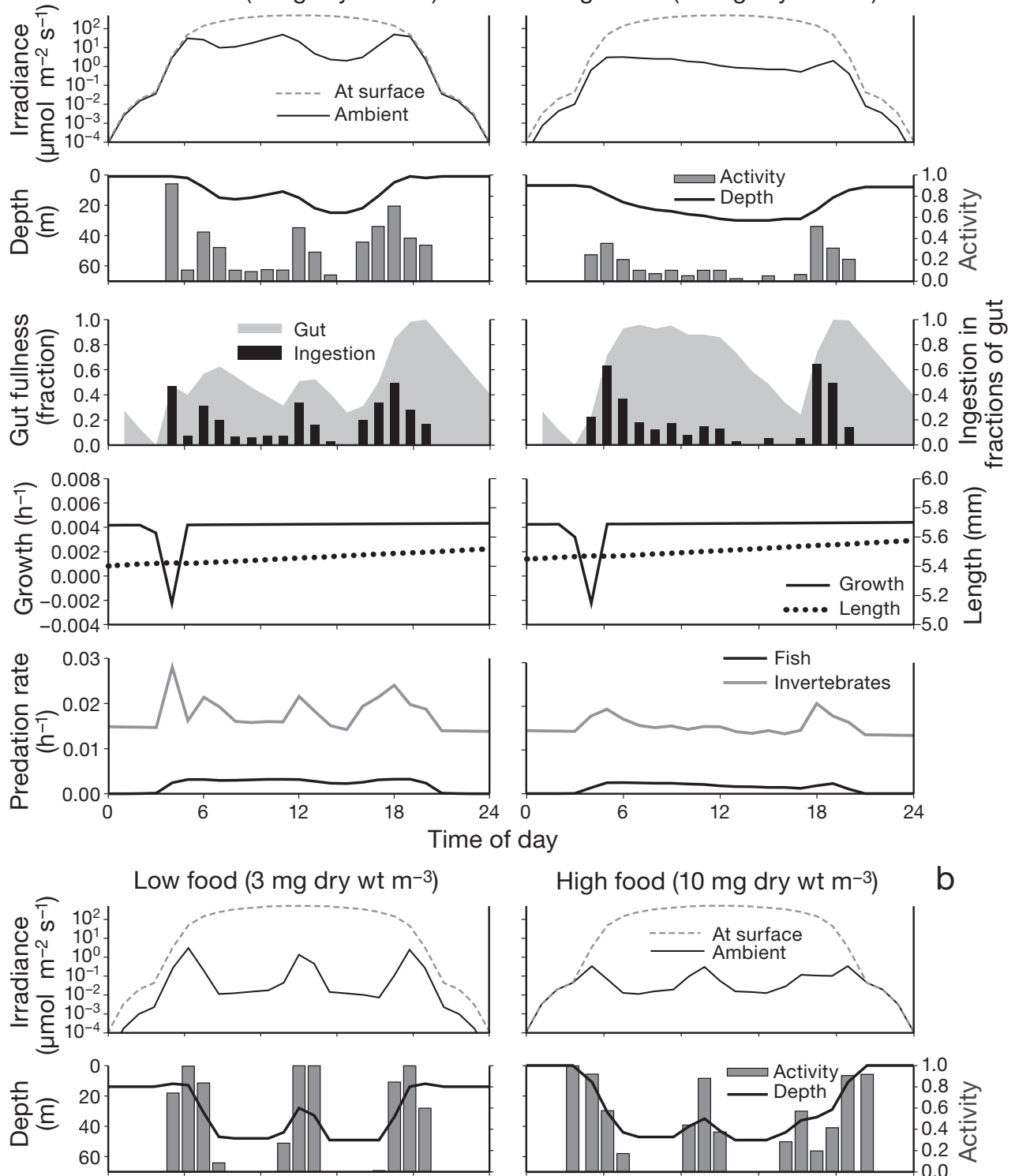

High food (10 mg dry wt $\left.\mathrm{m}^{-3}\right) \quad$ b

Fig. 3. Detailed view of individual behaviours, ingestion (in fractions of gut capacity $\left.\mathrm{h}^{-1}\right)$, gut fullness, growth $\left(\mathrm{h}^{-1}\right)$, body length and predation rates $\left(\mathrm{h}^{-1}\right)$ from fish and invertebrates (bottom panels) in relation to the diel irradiance cycle (top panels). Food was uniformly distributed in this simulation. The left panels show larvae at low food abundance ( $3 \mathrm{mg}$ dry $w \mathrm{t} \mathrm{m}^{-3}$ ), and right panels larvae at high food abundance (10 mg dry wt $\mathrm{m}^{-3}$ ). (a) Small and young larvae (5.5 mm); (b) larger larvae (9.5 to $10 \mathrm{~mm})$
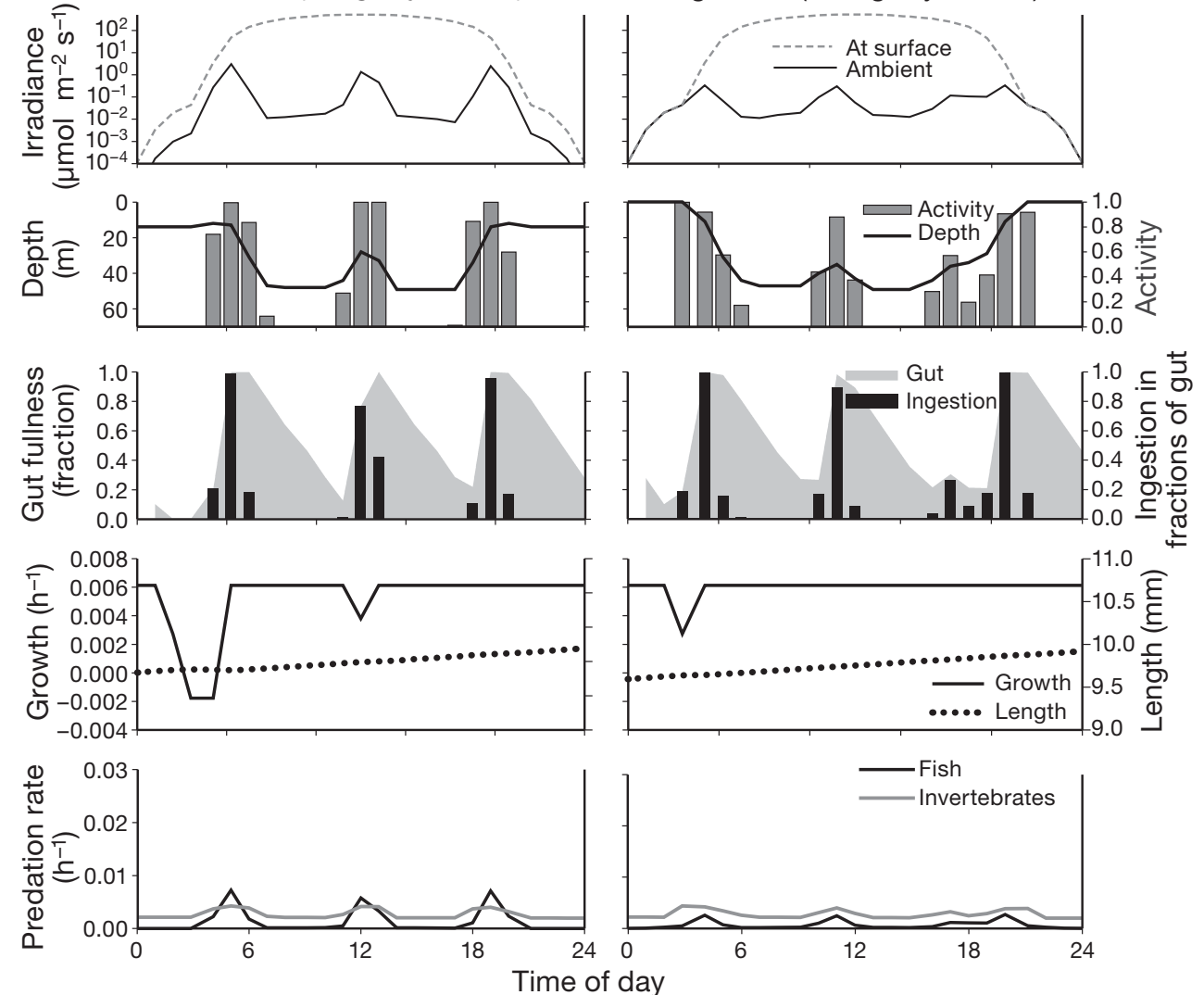
reducing the activity level required to fill their guts. Larger larvae are more easily detected by visual predators but their realized predation rate from fish is not higher since they descend to deeper and darker habitats.

The underlying trade-offs become clearer when comparing low and high food scenarios. Given that everything else stays constant, lower prey availability would lead to decreased gut fullness and thereby reduced growth. Behaviour compensates for this: in both high and low food concentrations, growth is rarely interrupted by empty guts. This is achieved by choosing shallower habitats and more active food search in the low food case, which increases foraging rates but also predation rates from both fish and invertebrates. The overall consequence is that growth can be maintained but at the cost of reduced survival.

Although the effect on predation rates seems small (Fig. 3), these rate differences are sustained for the entire larval phase. For larvae growing from 5 to $15 \mathrm{~mm}$, survival is $\sim 5$ times higher at 10 than at $3 \mathrm{mg}$ dry wt $\mathrm{m}^{-3}$ (Fig. 4).

\section{Growth, survival and recruitment success}

To quantify the implications of prey availability for recruitment success, we ran the model for a range of prey densities and recorded survival probability, time required and accumulated mortality rate for a larva grow- ing from 5 to $15 \mathrm{~mm}$ (Fig. 4). We did this for 3 different prey distribution patterns: a uniform prey distribution (as in Figs. 2 \& 3); and 2 cases where prey was normally distributed over depth, either with deep or shallow prey maximum (see Fig. 1). The uniform distribution pattern will of course always be superior to a peaked concentration with the same maximum in terms of larval growth and survival. Growth remains relatively stable as long as prey densities are above 3 to $5 \mathrm{mg}$ dry $\mathrm{wt} \mathrm{m}^{-3}$. When food increases from 3 to $30 \mathrm{mg}$ dry $\mathrm{wt} \mathrm{m}^{-3}$ in the uniform and shallow prey distribution scenarios, length at age $30 \mathrm{~d}$ reaches between 11 and $12 \mathrm{~mm}$ (Fig. 4a) and the time taken to reach $15 \mathrm{~mm}$ drops by about 5 days (Fig. 4b). Growth is slower when prey is deep, but qualitatively the pattern remains the same. The youngest larvae benefit from a shallow prey distribution (Fig. 4c), while larger larvae are better off with the deeper prey distribution as long as peak prey density exceeds $15 \mathrm{mg}$ dry wt $\mathrm{m}^{-3}$ (Fig. 4d). An increase in prey density from 3 to $30 \mathrm{mg}$ dry wt $\mathrm{m}^{-3}$ leads to an increase in survival from first feeding to $15 \mathrm{~mm}$ of around 1 order of magnitude for the shallow and uniform prey distributions and 2 orders of magnitude for deep prey distribution.

\section{Predation from invertebrates versus fish}

Prey distribution also has strong implications for the main source of mortality. If prey is deep, then larvae are safer from fish in the darker and deeper habitats,
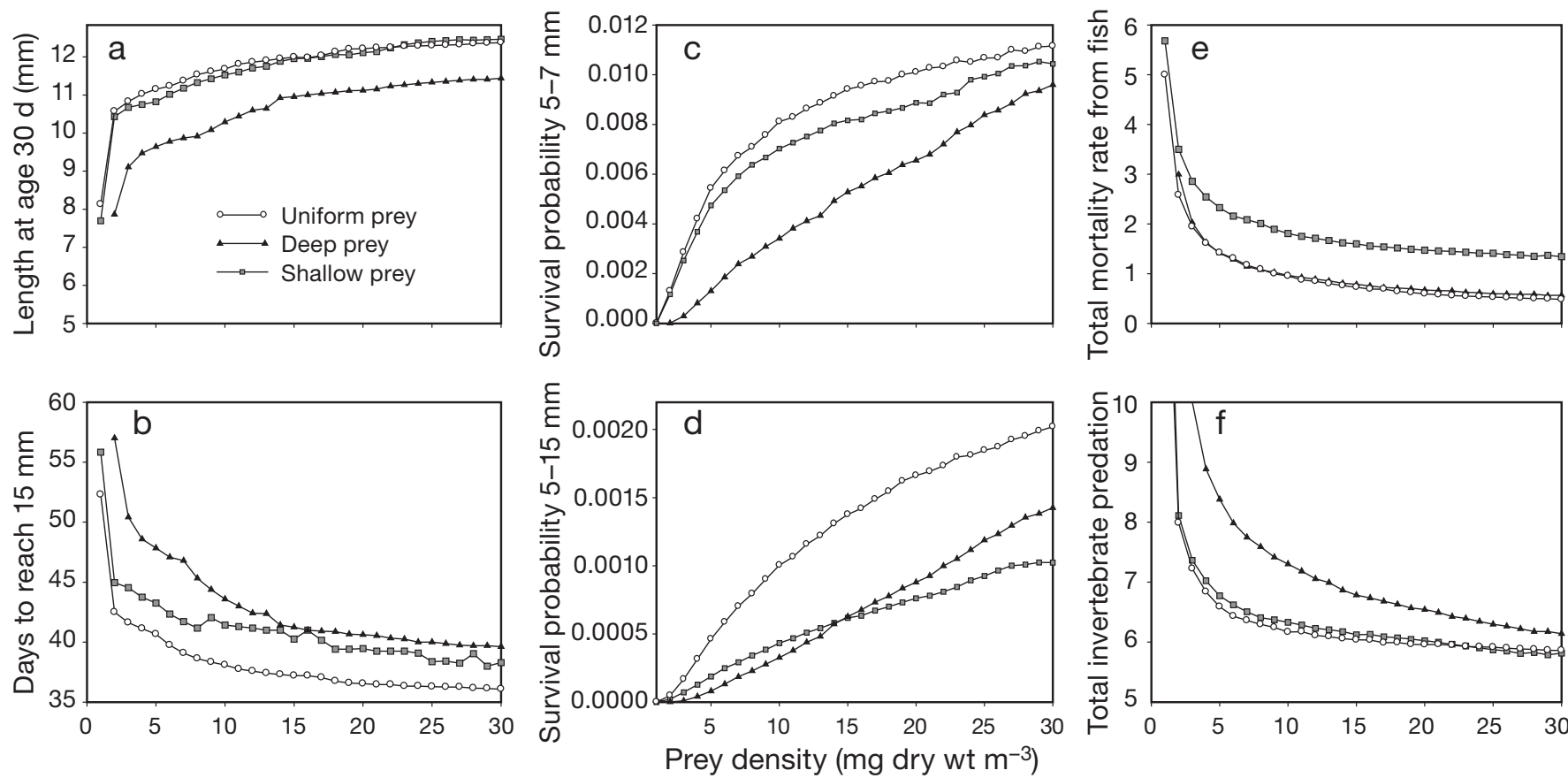

Fig. 4. Realizations of the model for shallow, uniform and deep prey distributions with prey abundance varying from 1 to 30 mg dry weight $\mathrm{m}^{-3}$. They show (a) length $(\mathrm{mm})$ at age $30 \mathrm{~d}$ (b) number of days required to reach $15 \mathrm{~mm}$ body length; survival probability to (c) $7 \mathrm{~mm}$ and (d) $15 \mathrm{~mm}$ body size, and total accumulated mortality rate from (e) fish and (f) invertebrates 
but they have to be more active to find enough food and are therefore more susceptible to invertebrates (Fig. 4e,f). In this scenario, larvae migrate less and grow slower and in sum accrue high death rates from invertebrates. The best strategy when prey distribution has a shallow peak is to take on less migration and activity, and instead remain nearer the surface. With uniform prey distribution the larvae have lower risk from the 2 predator sources (Fig. 4e,f).

Replacing the McGurk (1986) size dependency in predation vulnerability with a fixed low mortality rate of $0.24 \mathrm{~d}^{-1}$ gave growth and survival responses with food abundance quite similar to the basic version (not shown). In this case the optimal strategy is still to grow at high rates even though total mortality increases with size.

\section{DISCUSSION}

We applied a detailed, mechanistic model of a particular larval fish, Atlantic cod, to explore the influence of food abundance on behaviour, with particular focus on consequences for growth and survival. The model predicts a daily routine of vertical positioning and foraging activity, where a chain of mechanisms link behaviour, foraging, gut fullness, growth and survival. The model makes a clear prediction that prey abundance has relatively weak effects on larval growth and stage duration, but simultaneously exerts an extensive influence on survival. This occurs from the foraging-predation trade-off implicit in the mechanisms of habitat choice and activity level, and the inclusion of flexible and adaptive behaviour in the model. The model predicts reduced diel vertical migration activity under more food-limiting conditions, a direct parallel to the observation Huntley \& Brooks (1982) coined as 'better dead than unfed' for a migratory copepod.

The lesson from our model is 2-fold and simple. Firstly, larval fish will go to great lengths to maintain high growth rates if food availability decreases. Fish eggs and larvae are particularly vulnerable to predation for their size (McGurk 1986), and in evolutionary terms, the intense mortality rate can be viewed as an important motivation to maintain rapid growth. Mathematically, total mortality depends on mortality rate and stage duration, or the time until the larvae reaches a given body size. Although faster growth can only be achieved by accepting higher immediate predation rates, it will also shorten the duration during which mortality needs to be sustained. In our model, growth may decrease a little, but generally be maintained at high levels despite lower food abundance. This happens because there are ways to modify behaviour so that the increased instantaneous predation is offset by shorter development time.
Secondly, a related consequence is that increasing prey availability will continue to increase survival far beyond food levels where physiological satiation occurs. This coupling between zooplankton abundance and larval fish survival is probably difficult to detect in the wild as it requires estimates of mortality rates or recruitment success along with data on food availability, and each of these properties are notoriously difficult to quantify in the field (but see Beaugrand et al. 2003).

The success of fast growing, faster developing and larger larvae is often seen in field studies (e.g. Meekan \& Fortier 1996, Takasuka et al. 2004), and this is also apparent from our model (Fig. 4) and other models (e.g. Leising \& Franks 1999). In our model, this general pattern emerges despite explicit behavioural trade-offs between growth and survival, and increasing risk of predation from a particular predator (fish) with size. In most existing models, the benefit of growth is inevitable, as no trade-offs are included. The benefit of fast growth and short stage duration still remains in our model, because the organism is allowed to behave in a fitness-maximizing manner.

\section{Recruitment success and food availability}

It has been difficult to establish clear links between abundance of prey and larval growth in the field, such as for larval cod (Folkvord 2005). In addition, rearing larval cod in land-locked fjords (e.g. Folkvord et al. 1994) has demonstrated the ability of cod to grow at maximum rates at quite low food abundances. Yet, the study by Beaugrand et al. (2003) suggests a connection between zooplankton abundance and recruitment success of North Sea cod. Our model reconciles these apparently contradictory observations by suggesting that the increased prey availability reduces predation risk, while growth rates remain high through behavioural flexibility - increased prey search activity or selection of shallower and more illuminated habitat. In essence, this means that food limitation should only be detectable if foraging conditions are severely limiting for larval fish. Larvae will be geared towards high growth rates and take higher risks instead of prolonging larval stage duration.

Others have found some evidence of food-limited growth in larval cod, particularly in smaller larvae and if preferred prey items are scarce (Buckley \& Durbin 2006). Interestingly, they concluded (op. cit., p. 2758) that 'data suggest that rapid larval growth maybe a necessary but not sufficient requirement for production of a strong year class', which is the same functional relationship with food that our model predicts. As long as food is sufficient to maintain growth, increasing food levels will increase survival, making it 
more likely that recruitment will be strong. Their study also found a substantial influence of photoperiod on growth, and after correcting for day length, the influence of food on growth appears comparable to our predictions. To what degree larval cod growth is limited directly by food availability depends mainly on the ability of larvae to compensate for reduced prey encounter rates by increasing their activity or depth position. It may not be possible to compensate for a shorter daylight period through behaviour, and this constraint seems to make a clear signal in larval fish growth rates (Suthers \& Sundby 1996).

\section{Evaluation of model assumptions}

A model is only a caricature of a complicated reality, and the confidence one can attribute to predictions depends on compliance to the assumptions made. The critical assumptions for our model are (1) there is a strong trade-off between foraging and survival; (2) larvae have the ability to make flexible adjustments in vertical positioning and activity level; and (3) fish larvae experience high predation rates.

Trade-offs between foraging and survival

In the model we included mechanistic formulations of 2 trade-offs. First, the choice of vertical habitat determines the exposure to light, and light in turn increases both feeding rates and predation risk from fish. At a mechanistic level, light increases detection distance for visual search and thus encounter rates (e.g. Confer et al. 1978). For fish larvae, increasing light therefore implies more frequent encounters with their zooplankton prey, but also that visual predators, mainly fish, will detect the fish larvae more often. This tradeoff is established as the main driver of diel vertical migration in zooplankton (Pearre 2003) and fish (Clark \& Levy 1988, Rosland \& Giske 1994). Second, we assumed that swimming activity leads to more frequent encounters with prey, but also that the hydro-dynamic trails increase predation risk from invertebrates. Intuitively, such a trade-off must exist for ambush and tactile predators, for which the movement of prey is a substantial part of the encounter kernel (Kiørboe et al. 2010). We also assumed that invertebrate predation is size-dependent, as larger larvae have better swimming capabilities and therefore will be more likely to escape a predation attempt (Miller et al. 1988, Bailey \& Houde 1989). Many visual predators are also quite sensitive to moving objects (Wright \& O'Brien 1982), and swimming while there is sufficient light may therefore make the larvae more susceptible to visual predation, but this was not included in the model. In many species, an alternative trade-off, whereby anti-predator behaviours reduce search efficiency, would be foraging versus schooling (e.g. Sogard \& Olla 1997) or foraging versus time spent hiding at the bottom (Biro et al. 2006). It has also been shown that having a full gut may in itself be risky as it reduces predator evasion abilities (Lankford et al. 2001). Such effects of gut fullness or digestion rate may modify model predictions, but we anticipate only minor differences as predation in the current model mainly has effects during foraging, which is closely linked with gut fullness and digestion rates.

\section{Flexible behaviour}

In our optimality approach individuals may respond flexibly as a consequence of 2 assumptions: information about the environment and internal state is generously available, and the larvae are capable of accurate and fine-tuned behaviours. In reality, limited perception is used to assess their local environment and internal conditions, and the larvae respond according to adaptive rules that have emerged over evolutionary time scales under environmental fluctuations. One benefit of an optimality approach is that we need not know or quantify the precise rules that organisms use, but rely on evolution to have equipped organisms with efficient behaviours. The true constraints appear more clearly when mechanisms are modelled explicitly (McNamara \& Houston 2009).

Our model implicitly assumes that larvae have global knowledge about mortality and foraging rates in the entire water column at all times. Although one cannot directly quantify what information fish larvae have, indirect evidence suggests that they are capable of information acquisition and use, as vertical migration patterns change in response to environmental conditions (Olivar et al. 2001, Voss et al. 2007) and in response to the presence of predators (Sogard \& Olla 1997, Skajaa et al. 2003, 2004). Evidence from laboratory studies also suggests that fish larvae have information about their internal state. For example, larval cod adjust their feeding behaviour with stomach fullness (MacKenzie \& Kiørboe 1995, Munk 1995), which can be interpreted both as a way of saving energy and to reduce risk of predation. One might also question the behavioural capability of the youngest larval fish to remain at preferred depths, particularly in well-mixed water columns or close to the surface where turbulence from wave action is stronger. The youngest larvae are also in an early ontogenetic state, which limits their perceptive and cognitive abilities. There is a rich body of theory and knowledge on zooplankton behaviour in vertical environmental gradients (reviewed in Pearre 
2003), and although phylogenetically distinct, fish larvae soon achieve comparable cognitive and locomotory abilities, so some generalizations seem defensible. Warm water fish may be behaviourally more capable than those from colder waters (Leis 2007), while the vertical gradients to act upon may be less steep in clear water.

\section{High predation rates}

Predation rates appear to be particularly high among larval fish compared to other pelagic organisms of similar size, and there is also a stronger decline in predation rates with size for fish larvae, usually explained by them being less developed than adults of comparable size (McGurk 1986). Generally, the size dependency of predation rates in pelagic systems is typically explained by mass balance considerations (Andersen \& Beyer 2006) and increasing escape capabilities along the size spectrum. The nature of the size dependency also differs between predators (Bailey \& Houde 1989). Invertebrate predators soon become inefficient in capturing larger larvae, while fish, relying on vision to locate their prey, may prefer larger larvae. In both cases, larval behaviour can change the overall level and the size dependency of predation risk. In the absence of behaviour, larger larvae will be more vulnerable to fish predators in our model. An unresolved issue is how day-night variability in the depth distribution of invertebrate predators may change the fitness landscape for larvae.

\section{Concepts in fisheries oceanography}

In terms of behavioural ecology, growth and mortality interact through some trade-off between them, implying that survival will decrease when growth is increased, assuming everything else being equal (Conover \& Schultz 1997). A seemingly contrasting perspective is often found within fisheries oceanography, where the environment is generally thought to be the driving force, such that growth inevitably varies with environmental conditions and therefore survival will increase when growth is increased. Both these perspectives are to some degree correct, but they are formulated to focus on different aspects of a more complicated reality. Fisheries oceanography compares across environmental conditions, where better food conditions may increase growth, reduce stage duration, and thereby increase survival. This has led to the emergence of concepts such as the 'bigger-is-better', 'growth-selective' and 'stage-duration' hypotheses (critically reviewed in Leggett \& Frank 2008), where size-dependent predation and environmental effects on growth are the main mechanisms. Assuming that behaviour stays constant, this line of thinking involves a causal chain of events from environment to growth to survival. The perspective of behavioural ecology challenges this view by focusing on what happens within a given environment - when the only way to increase growth is often to accept reduced survival. Here the causal chain is from environment to behaviour, which in turn affects growth and survival jointly but not necessarily with linear or proportional outcomes. Our model combines these 2 perspectives as it predicts quantitative and adaptive changes in behaviour, with consequences for growth and survival, if there is a change in the environmental conditions. Survival changed over a wide range of food concentrations, whereas growth did not change much because larvae adjusted vertical position and swimming behaviour to reduce risk rather than to grow faster.

The theory of risk-sensitive foraging is well established (e.g. McNamara \& Houston 1987, Houston et al. 1993). In our model, we have tried to mimic the conditions and trade-offs for larval fish in the pelagic, and in particular, mixed 2 sources of predation with opposite size dependency of predation risk. Although larvae become more vulnerable to predation from fish as they grow larger, they have lower migration costs and therefore can hide more in the deep. The realized predation and growth rates over larval ontogeny emerge from a mixture of behavioural decisions, ecological mechanics and physiological or environmental constraints. Although bigger is not better in terms of immediate survival from the mechanics, the optimal strategy is to grow at near maximal rates under practically all conditions where this is possible. It appears that it is optimal to accept higher predation rather than lower growth rates in the larval fish environments we have focused on here. This may extend beyond the larval stage and into juveniles, where many growth and survival tradeoffs have been identified (Sogard 1997).

\section{CONCLUSION}

Clear relationships between growth rates and prey availability may be difficult to establish for larval fish, but the scarcity of such findings does not mean prey is not important to recruitment success. Given high predation risk and flexible, risk-sensitive foraging behaviour, fish larvae will have a strong motivation to maintain high growth rates. The importance of prey availability cannot be assessed by the impact it has on growth rates, since the effects of prey abundance will appear in predation rates, not in growth. For organisms facing growth-predation trade-offs, resource availabil- 
ity will have an impact on recruitment success far beyond physiological satiation levels.

Our model embraces and unifies several concepts from fisheries oceanography. It emphasizes the role of 'match and mismatch' with prey resources, since prey can be more important to recruitment success than what is predicted from 'stage-duration', 'growth-mortality' or 'bigger-is-better' arguments.

Acknowledgements. We thank A. Folkvord, D. L. Aksnes, A. Urtizberea, A. F. Opdal and 3 anonymous reviewers for valuable comments and discussions, and the Norwegian Research Council for financial support.

\section{LITERATURE CITED}

Aksnes DL, Utne ACW (1997) A revised model of visual range in fish. Sarsia 82:137-147

Andersen KH, Beyer JE (2006) Asymptotic size determines species abundance in the marine size spectrum. Am Nat 168:54-61

Arendt JD (1997) Adaptive intrinsic growth rates: An integration across taxa. Q Rev Biol 72:149-177

Bailey KM, Houde ED (1989) Predation on eggs and larvae of marine fishes and the recruitment problem. Adv Mar Biol 25:1-83

Beaugrand G, Brander KM, Lindley JA, Souissi S, Reid PC (2003) Plankton effect on cod recruitment in the North Sea. Nature 426:661-664

Biro PA, Abrahams MV, Post JR, Parkinson EA (2006) Behavioural trade-offs between growth and mortality explain evolution of submaximal growth rates. J Anim Ecol 75: 1165-1171

Buckley LJ, Durbin EG (2006) Seasonal and inter-annual trends in the zooplankton prey and growth rate of Atlantic cod (Gadus morhua) and haddock (Melanogrammus aeglefinus) larvae on Georges Bank. Deep-Sea Res II 53: 2758-2770

Clark CW, Levy DA (1988) Diel vertical migrations by juvenile sockeye salmon and the antipredation window. Am Nat 131:271-290

Confer JL, Howick GL, Corzette MH, Kramer SL, Fitzgibbon S, Landesberg R (1978) Visual predation by planktivores. Oikos 31:27-37

Conover D, Schultz ET (1997) Natural selection and the evolution of growth rate in the early life history: what are the trade-offs? In: Chambers RC, Trippel EA (eds) Early life history and recruitment in fish populations. Chapman \& Hall, London, p 305-332

> Cushing DH (1990) Plankton production and year-class strength in fish populations: an update of the match/mismatch hypothesis. Adv Mar Biol 26:249-293

> Dmitriew CM (2011) The evolution of growth trajectories: what limits growth rate? Biol Rev Camb Philos Soc 86: 97-116

Fiksen Ø, MacKenzie BR (2002) Process-based models of feeding and prey selection in larval fish. Mar Ecol Prog Ser 243:151-164

Fiksen Ø, Jørgensen C, Kristiansen T, Vikebø F, Huse G (2007) Linking behavioural ecology and oceanography: larval behaviour determines growth, mortality and dispersal. Mar Ecol Prog Ser 347:195-205

Folkvord A (2005) Comparison of size-at-age of larval Atlantic cod (Gadus morhua) from different populations based on size- and temperature-dependent growth models. Can J Fish Aquat Sci 62:1037-1052

Folkvord A, Øiestad V, Kvenseth PG (1994) Growth patterns of three cohorts of Atlantic cod larvae (Gadus-morhua L) studied in a macrocosm. ICES J Mar Sci 51:325-336

Hjort J (1914) Fluctuations in the great fisheries of Northern Europe viewed in the light of biological research. Rapp P-V Reùn Cons Int Explor Mer 20:1-228

Houde E (1997) Patterns and consequences of selective processes in teleost early life histories. In: Chambers RC, Trippel EA (eds) Early life history and recruitment in fish populations. Chapman \& Hall, London, p 173-196

Houston AI, McNamara J (1999) Models of adaptive behaviour. An approach based on state. Cambridge University Press, Cambridge

Houston AI, Mcnamara JM, Hutchinson JMC (1993) General results concerning the trade-off between gaining energy and avoiding predation. Philos Trans R Soc Lond B 341: 375-397

Huntley M, Brooks ER (1982) Effects of age and food availability on diel vertical migration of Calanus pacificus. Mar Biol 71:23-31

Huse G, Fiksen $\varnothing$ (2010) Modelling encounter rates and distribution of mobile predators and prey. Prog Oceanogr 84: 93-104

Kiørboe T (2008) A mechanistic approach to plankton ecology. Princeton University Press, Princeton, NJ

- Kiørboe T, Jiang H, Colin SP (2010) Danger of zooplankton feeding: the fluid signal generated by ambush-feeding copepods. Proc R Soc Lond B Biol Sci 277:3229-3237

- Kristiansen T, Fiksen Ø, Folkvord A (2007) Modelling feeding, growth, and habitat selection in larval Atlantic cod (Gadus morhua): observations and model predictions in a macrocosm environment. Can J Fish Aquat Sci 64:136-151

> Kristiansen $\mathrm{T}$, Jørgensen C, Lough RG, Vikebø F, Fiksen $\varnothing$ (2009) Modeling rule-based behavior: habitat selection and the growth-survival trade-off in larval cod. Behav Ecol 20:490-500

Lankford TE, Billerbeck JM, Conover DO (2001) Evolution of intrinsic growth and energy acquisition rates. II. Tradeoffs with vulnerability to predation in Menidia menidia. Evolution 55:1873-1881

Leggett WC, Frank KT (2008) Paradigms in fisheries oceanography. Oceanogr Mar Biol Annu Rev 46:331-363

Leis J (2007) Behaviour of fish larvae as an essential input for modelling larval dispersal: behaviour, biogeography, hydrodynamics, ontogeny, physiology and phylogeny meet hydrography. Mar Ecol Prog Ser 347:185-193

> Leising AW, Franks PJS (1999) Larval Atlantic cod (Gadus morhua) and haddock (Melanogrammus aeglefinus) growth on Georges Bank: a model with temperature, prey size, and turbulence forcing. Can J Fish Aquat Sci 56: 25-36

- MacKenzie BR, Kiørboe T (1995) Encounter rates and swimming behavior of pause-travel and cruise larval fish predators in calm and turbulent laboratory environments. Limnol Oceanogr 40:1278-1289

Mangel M, Clark CW (1988) Dynamic modeling in behavioral ecology. Princeton University Press, Princeton, NJ

McGurk MD (1986) Natural mortality of marine pelagic fish eggs and larvae: role of spatial patchiness. Mar Ecol Prog Ser 34:227-242

- McNamara JM, Houston AI (1987) Starvation and predation as factors limiting population size. Ecology 68:1515-1519

- McNamara JM, Houston AI (2009) Integrating function and mechanism. Trends Ecol Evol 24:670-675 
Meekan MG, Fortier L (1996) Selection for fast growth during the larval life of Atlantic cod Gadus morhua on the Scotian Shelf. Mar Ecol Prog Ser 137:25-37

Miller TJ, Crowder LB, Rice JA, Marschall EA (1988) Larval size and recruitment mechanisms in fishes: toward a conceptual framework. Can J Fish Aquat Sci 45:1657-1670

Munk P (1995) Foraging behavior of larval cod (Gadus morhua) influenced by prey density and hunger. Mar Biol 122:205-212

Munk P (1997) Prey size spectra and prey availability of larval and small juvenile cod. J Fish Biol 51:340-351

> Olivar MP, Salat J, Palomera I (2001) Comparative study of spatial distribution patterns of the early stages of anchovy and pilchard in the NW Mediterranean Sea. Mar Ecol Prog Ser 217:111-120

Pearre S (2003) Eat and run? The hunger/satiation hypothesis in vertical migration: history, evidence and consequences. Biol Rev Camb Philos Soc 78:1-79

Pedersen T, Falk-Petersen IB (1992) Morphological changes during metamorphosis in cod (Gadus morhua L.), with particular reference to the development of the stomach and pyloric caeca. J Fish Biol 41:449-461

Perez KO, Munch SB (2010) Extreme selection on size in the early lives of fish. Evolution 64:2450-2457

Rosland R, Giske J (1994) A dynamic optimization model of the diel vertical distribution of a pelagic planktivorous fish. Prog Oceanogr 34:1-43

Skajaa K, Ferno A, Folkvord A (2003) Swimming, feeding and predator avoidance in cod larvae (Gadus morhua L.): trade-offs between hunger and predation risk. In: Brow-

Editorial responsibility: Roger Hughes,

Bangor, UK man HI, Skiftesvik AB (eds) The big fish bang. Institute of Marine Research, Bergen, p 105-121

Skajaa K, Ferno A, Folkvord A (2004) Ontogenetic- and condition-related effects of starvation on responsiveness in herring larvae (Clupea harengus L.) during repeated attacks by a model predator. J Exp Mar Biol Ecol 312:253-269

Sogard SM (1997) Size-selective mortality in the juvenile stage of teleost fishes: a review. Bull Mar Sci 60:1129-1157

Sogard SM, Olla BL (1997) The influence of hunger and predation risk on group cohesion in a pelagic fish, walleye pollock Theragra chalcogramma. Environ Biol Fishes 50: 405-413

Suthers IM, Sundby S (1996) Role of the midnight sun: Comparative growth of pelagic juvenile cod (Gadus morhua) from the Arcto-Norwegian and a Nova Scotian stock. ICES J Mar Sci 53:827-836

Takasuka A, Aoki I, Mitani I (2003) Evidence of growth-selective predation on larval Japanese anchovy Engraulis japonicus in Sagami Bay. Mar Ecol Prog Ser 252:223-238

- Takasuka A, Oozeki Y, Kimura R, Kubota H, Aoki I (2004) Growth-selective predation hypothesis revisited for larval anchovy in offshore waters: cannibalism by juveniles versus predation by skipjack tunas. Mar Ecol Prog Ser 278: 297-302

> Voss R, Schmidt JO, Schnack D (2007) Vertical distribution of Baltic sprat larvae: changes in patterns of diel migration? ICES J Mar Sci 64:956-962

Wright DI, O'Brien WJ (1982) Differential location of Chaoborus larvae and Daphnia by fish: the importance of motion and visible size. Am Midl Nat 108:68-73

Submitted: November 5, 2010; Accepted: March 25, 2011 Proofs received from author(s): May 27, 2011 